\title{
LINKING THE LOCAL CLIMATE ZONES AND LAND SURFACE TEMPERATURE TO INVESTIGATE THE SURFACE URBAN HEAT ISLAND, A CASE STUDY OF SAN ANTONIO, TEXAS, U.S.
}

\author{
C. Zhao* \\ Department of Geography, Texas State University, San Marcos, 78666, USA - zhaoch@txstate.edu
}

KEY WORDS: Local Climate Zones, Land Surface Temperature, Urban Heat Island, San Antonio, Regression analysis, Lidar

\begin{abstract}
:
The Local Climate Zones (LCZs) concept was initiated in 2012 to improve the documentation of Urban Heat Island (UHI) observations. Despite the indispensable role and initial aim of LCZs concept in metadata reporting for atmospheric UHI research, its role in surface UHI investigation also needs to be emphasized. This study incorporated LCZs concept to study surface UHI effect for San Antonio, Texas. LCZ map was developed by a GIS-based LCZs classification scheme with the aid of airborne Lidar dataset and other freely available GIS data. Then, the summer LST was calculated based Landsat imagery, which was used to analyse the relations between LST and LCZs and the statistical significance of the differences of LST among the typical LCZs, in order to test if LCZs are able to efficiently facilitate SUHI investigation. The linkage of LCZs and land surface temperature (LST) indicated that the LCZs mapping can be used to compare and investigate the SUHI. Most of the pairs of LCZs illustrated significant differences in average LSTs with considerable significance. The intra-urban temperature comparison among different urban classes contributes to investigate the influence of heterogeneous urban morphology on local climate formation.
\end{abstract}

\section{INTRODUCTION}

Urbanization and the related environmental issues have been continuously drawing attention worldwide in previous decades. In the urban expansion process, natural landscapes are replaced by built-up land and impervious surfaces, which changes energy absorption, storage, emittance, wind turbulence intensity, humidity, and anthropogenic energy release, etc. (Oke 1976, Mirzaei 2015). This phenomenon was described as Urban Heat Island (UHI), meaning that urban area is warmer than the surrounding rural area. UHIs are continuously drawing attention since they were first described in the 1810s (Howard 1818).

There are two types of UHI studies: atmospheric UHI (AUHI) and surface UHI (SUHI). Traditional UHI investigation has focused on AUHI, where the air temperature pattern in an urban area is generally compared to rural areas based on field measurements at isolated fixed or mobile stations. Although some modern devices can capture additional parameters like velocity, turbulence, and even pollution concentration, limited and isolated stationary networks are not capable of capturing heterogeneous thermal characteristics caused by land use and land cover (LULC) (Hu and Brunsell 2015, Shen, Huang et al. 2016). In contrast to the direct AUHI measurement, SUHI is an indirect measurement by investigating the land surface temperature (LST). LST data is time-synchronized and gridbased for a considerable areal extent (Nichol 1996). So far, various remote sensing sensors have been used to estimate LST with thermal infrared band/bands from coarse to fine spatial resolution (Table 1).

However, there are no systematic criteria for experimental design and communication for UHI observation. Methods to obtain representative measurements of UHI have been discussed and utilized in previous studies (Nunez and Oke 1977), but there are still no standardized observation protocols for UHI intensity estimation, preventing synthesis and comparisons among UHI studies.

\begin{tabular}{|c|c|c|}
\hline Sensors & $\begin{array}{c}\text { Spatial resolution } \\
\text { of thermal } \\
\text { band(s) }\end{array}$ & $\begin{array}{c}\text { Temporal } \\
\text { resolution }\end{array}$ \\
\hline $\begin{array}{c}\text { Advanced Very High } \\
\text { Resolution Radiometer } \\
\text { (AVHRR) }\end{array}$ & $1.1 \mathrm{~km}$ & $\begin{array}{c}\text { Twice } \\
\text { daily }\end{array}$ \\
\hline $\begin{array}{c}\text { MODerate resolution } \\
\text { Imaging } \\
\text { Spectroradiometer } \\
\text { (MODIS) }\end{array}$ & $\begin{array}{c}\text { Approximately 1 } \\
\mathrm{km}\end{array}$ & $\begin{array}{c}\text { Twice } \\
\text { daily }\end{array}$ \\
\hline $\begin{array}{c}\text { Advanced Along Track } \\
\text { Scanning Radiometer } \\
\text { (AATSR) }\end{array}$ & $1 \mathrm{~km}$ & 35 days \\
\hline $\begin{array}{c}\text { Advanced Space borne } \\
\text { Thermal Emission and } \\
\text { Reflection Radiometer } \\
\text { (ASTER) }\end{array}$ & $90 \mathrm{~m}$ & 16 days \\
\hline $\begin{array}{c}\text { Thematic Mapper (TM), } \\
\text { Enhanced Thematic } \\
\text { Mapper Plus (ETM }+ \text { ) }\end{array}$ & $30 \mathrm{~m}$ after & 16 days \\
\hline $\begin{array}{c}\text { Thermal Infrared Sensor } \\
\text { (TIR) }\end{array}$ & $30 \mathrm{~m}$ after & 16 days \\
\hline
\end{tabular}

Table 1. Different remote sensing sensors for urban thermal studies

The Local Climate Zones (LCZ) concept was initiated to improve the documentation of atmospheric UHI observations in 2012 (Stewart and Oke 2012). LCZs are defined as "regions of uniform land cover, surface structure, construction material, and human activity that span hundreds of meters to several kilometres on a horizontal scale" (Stewart and Oke 2012) (p. 1884). The LCZ classification intends to standardize the worldwide exchange of urban temperature observations. The 17 standard LCZ classes

\footnotetext{
* Corresponding author
} 
(Table A1, appendix) are determined by their surface characteristics, including: composition (building/tree), structure (permeability), fabric (albedo, thermal admittance), and metabolism (e.g., Table 2 on p. 1885 of (Stewart and Oke 2012)). Unique combinations of these properties provide a distinctive thermal regime for each LCZ (Stewart and Oke 2012, Geletič, Lehnert et al. 2016).

Despite the indispensable role and initial aim of LCZs concept in metadata reporting for AUHI research (Stewart, Oke et al. 2014), its role in SUHI investigation also needs to be emphasized. First, the AUHI research could not make full use of the spatial coverage character of LCZ concept. In contrast, remotely sensed LST is time-synchronized and complete spatial coverage to a considerable areal extent (Nichol 1996), which match the spatial coverage of LCZs concept. Furthermore, LST is affected by underlying physical factors (e.g., urban geometry, land cover properties) as well as dynamic factors (e.g., human interaction, intervention of surrounding area) in the reality. These factors modify the microclimate of the urban area and urban energy balance within the UCL, which is also a challenge for to investigate the SUHI intensity. Thus, if LCZs can be mapped in practice for a specific area (areas), the connection between LST and LCZ can help to test the applicability of LCZs concept for SUHI study, and further help to understand the influence of LCZs on SUHI spatial variation.

Compared to studies on LCZs mapping, rarely litter work has been done to comprehensively access the applicability of LCZ on local climate study. Geletič, Lehnert et al. (2016) explored the extent to which LCZ classes discriminate with respect to LSTs based on two central European cities and found that different LCZ classes have different LST characteristics. Cai, Ren et al. (2017) determined the relationship between LST and LCZs at Yangtze River Delta (YRD) mega-region in China. Kotharkar and Bagade (2017) accessed the inter-LCZ temperature difference and identifies LCZs at Nagpur city with stationary meteorological mobile surveys. However, a comprehensive assessment of LCZs mapping needs more deep understanding and spatial analysis of the extent to which LCZ classes discriminate with respect to LSTs for different places.

This study will incorporate LCZs concept to study and compare SUHI effect for San Antonio by answering the following research question, "How the SUHI vary in San Antonio and how can LCZs be used to improve the characterization of SUHI?" To answer the question, the LCZ map were developed by a GISbased LCZs classification scheme with the aid of airborne Lidar dataset and other freely available GIS data. Then, the summer LST were calculated based Landsat imagery, which is used to analyse the relations between LST and LCZs, statistical significance of the differences of LST among the typical LCZ, in order to test if LCZs are able to efficiently facilitate SUHI investigation of San Antonio.

\section{DATA AND METHOD}

\subsection{Study Area}

This study focuses on the entire metropolitan area of San Antonio in in south central Texas, U.S. San Antonio metropolitan area is located in a unique and narrow transitional zone that ranges from semi-arid vegetation cover dominated by trees and shrubs in the west to humid and more densely vegetated prairie/grassland to

\footnotetext{
${ }^{1}$ US News, http://realestate.usnews.com/realestate/slideshows/the-best-places-to-live-in-the-us-in-2017/
}

the east The topography is high in the northwest part (Edwards Plateau) and low in the southeast part (Gulf Coastal Plains). It is 130 kilometres away from Austin. Interstate highways (I-35) connect San Antonio to major cities of Texas and Mexico. The city is known by Texas history, culture, and downtown beauty, and it attracts more than one million tourists per year (Bremer 2004).

San Antonio demonstrates UHI effects and higher summer temperatures (Table 2). It is among the top 25 ranked best to live in US cities ${ }^{1}$. However, there has been limited documentation of UHI studies. The Interstate highway 35 (I-35) passes through the city of San Antonio. With a transitional humid subtropical climate, the average annual temperature from 1981-2010 was $20.8^{\circ} \mathrm{C}$. The highest temperature recorded was $44^{\circ} \mathrm{C}$ in 2000 . May, June, and October tend to be the months of greatest precipitation, with an annual average of $737 \mathrm{~mm}$ since recording started in 1871. Regarding UHI effect, the downtown San Antonio area has been shown to exhibit higher temperatures than the surrounding areas as reported by Xie, Guan et al. (2005).

\begin{tabular}{|c|c|c|c|}
\hline & June & July & August \\
\hline Average high temperature $\left({ }^{\circ} \mathrm{C}\right)$ & 33 & 34.8 & 34.8 \\
\hline Average low temperature $\left({ }^{\circ} \mathrm{C}\right)$ & 22 & 23.3 & 23.1 \\
\hline Average precipitation $(\mathrm{mm})$ & 109 & 52 & 65 \\
\hline
\end{tabular}

Table 2. Summer monthly air temperature and precipitation summary of San Antonio ${ }^{2}$

\subsection{Local Climatic Zone Mapping}

With free available NLCD and Lidar dataset, the development of GIS-based LCZs classification scheme was mainly based on the LCZs definition and LCZs delineation criteria by Stewart and Oke (2012). Height of roughness, building surface fraction, Impervious surface fraction (ISF), pervious surface fraction (PSF), sky view factor (SVF), and terrain roughness class are all demonstrated of importance, for LCZs mapping (Unger, Lelovics et al. 2014, Geletič and Lehnert 2016, Zheng, Ren et al. 2017). Figure 1 shows the overall LCZs mapping scheme by considering different properties in each step. Lidar dataset was gathered from Texas Natural Resources Information System (TNRIS ${ }^{3}$ ), downloaded manually per tile online, or derived and transferred directly through hard drive. The metadata is showed in Table A1 in the appendix. Subsequently, the decision-making algorithm was built for LCZs mapping, and LCZs datasets were established.

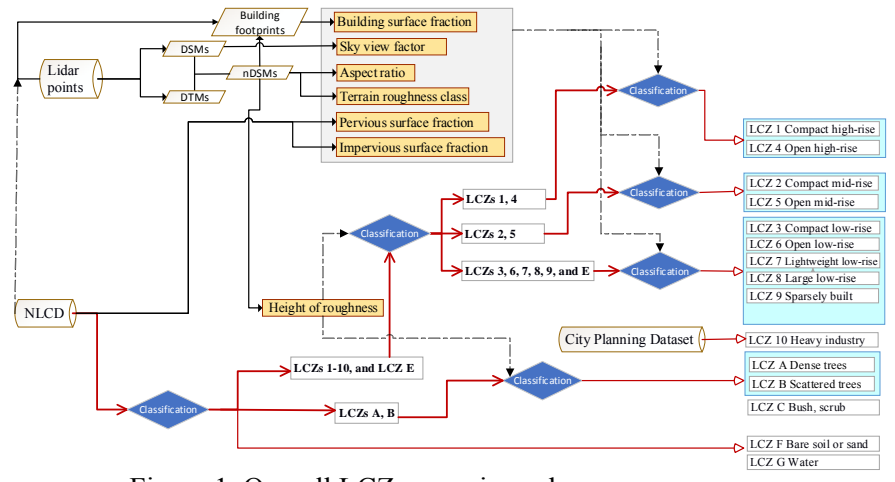

Figure 1. Overall LCZs mapping scheme

${ }^{2}$ Source: U.S. climate, http://www.usclimatedata.com/

${ }^{3}$ https://tnris.org/. 


\subsection{Land Surface Temperature Calculation}

Considering the obvious adverse impact on the human comfort of hot weather for cities in the tropical and subtropical region of the northern hemisphere at summer, here we focus on the SUHI phenomenon during the summer months Landsat 8 image of summer 2015 for were obtained to calculate LST to investigate the SUHI phenomenon. The TIRS sensor on Landsat 8 has two thermal infrared bands in the atmospheric window between 10 and $12 \mu \mathrm{m}$. Several algorithms (e.g., Plank function, radiative transfer equation, split-window algorithm, single channel algorithm) can be used to invert LST (Jiménez-Muñoz et al. 2014). A recent study suggested that the Planck function and the single channel algorithm showed the best performance for Landsat 8 TIRS though comparing the different algorithms of LST extraction (Isaya Ndossi and Avdan 2016). In this study, we applied the Planck function for LST calculation and use the normalized LST for SUHI comparison for three study areas. Considering band 11 is associated with higher calibration uncertainty and more sensitive to water vapor continuum absorption (Coll et al. 2012; Yu et al. 2014), LSTs were computed based on band 10 for this study.

First, the Top of Atmosphere (TOA) radiance (e.g., radiance measured by the sensor, $L_{T O A, \lambda}$ ) was converted to brightness temperature with the following equation.

$$
T_{\text {sen }}=\frac{K 2}{\ln \left(\frac{K 1}{L_{T O A, \lambda}}+1\right)}
$$

where $T_{s e n}$ is temperature in Kelvin $(\mathrm{K})$, and $\mathrm{K}_{1}$ and $\mathrm{K}_{2}$ are calibration constants specific to the Landsat TIRS sensor, which can be obtained from the metadata of the imagery.

The brightness temperature was further corrected against the land surface emissivity (LSE), which is essential for LST inversion due to the notable thermal variation of different land surface properties at a large spatial extent. The variation of vegetation coverage, surface moisture, surface roughness, and viewing angles leads to different LSEs for different cover types (Yu et al. 2014). The normalized difference vegetation index (NDVI) threshold emissivity estimation algorithm (Sobrino et al. 1990; Sobrino et al. 2004), a common method for LSE estimates was applied in this study. The NDVI values were used to distinguish between soil and vegetated pixels before LSE calculation. The TOA radiance values converted from digital number of band 4 (Red) and band 5 (NIR) from Landsat OLI were used for correspondent NDVI calculation to mitigate the effect from vegetation phenology.

The threshold of NDVI of rocks/soil $\left(N D V I_{S}\right)$ was assigned with a value of 0.2 , and the threshold of NDVI of vegetation $\left(N D V I_{v}\right)$ was assigned with a value of 0.5 (Sobrino, Jiménez-Muñoz et al. 2004). For a pixel with calculated NDVI from Landsat 8 OLI, if its NDVI $<N D V I_{v}$, then we assume that the pixel is composed of bare soil or rock. And if its NDVI $>N D V I_{v}$, we assume that it is composed of full vegetation cover. Then, LSE value was assigned to these pixels accordingly. Otherwise, this pixel is considered to be the composition of the vegetation and rocks/soil:

$$
\varepsilon_{\lambda}=\varepsilon_{v \lambda} P_{V}+\varepsilon_{s \lambda}\left(1-P_{V}\right)+C_{\lambda}
$$

where $\varepsilon_{v \lambda}$ is emissivity of vegetation. $\varepsilon_{s \lambda}$ is emissivity of soil. $C_{\lambda}$ takes into consideration the cavity effect due to surface roughness.

$$
C_{\lambda}=\left(1-\varepsilon_{s \lambda}\right) \varepsilon_{v \lambda} F^{\prime}\left(1-P_{V}\right)
$$

where $F^{\prime}$ is a geometrical factor (with range from 0 to 1 ), while $P_{V}$ is vegetation fraction.

$$
P_{V}=\left[\frac{N D V I-N D V I_{\min }}{N D V I_{\max }-N D V I_{\min }}\right]^{2}
$$

The Planck's function was used to perform for LSE correction of the substance compared to the blackbody. Thus, the value of brightness temperature was converted to LST (Artis and Carnahan 1982; Isaya Ndossi and Avdan 2016).

$$
T s=\frac{B_{T}}{1+\frac{\lambda B_{T}}{\rho} \ln \varepsilon_{\lambda}}
$$

where Ts is LST in Kelvin (K), and $B_{T}$ is brightness temperature (e.g., Tsen) in this study. $\lambda$ is the wavelength of emitted radiance (band 10 was used for LST calculation, and $\lambda=10.895 \mu \mathrm{m}$ for Landsat 8 TRIS), $\rho$ (e.g., $\left.\frac{h * c}{\sigma}\right)=1.438 \times 10^{-2} \mathrm{mK}$. Ts was then converted into Celsius LST $\left({ }^{\circ} \mathrm{C}\right)$.

\subsection{SUHI investigation based on LCZs}

To explore the application of LCZ mapping for SUHI characterization, our hypothesis is that each LCZ demonstrates unique and typical LST character, and LCZs can intercomparisons for SUHI intensity for the metropolitan area. To get independent observations for the following statistical test and exploration, we first explored the autocorrelation scale of the LST pixels with a $30 \mathrm{~m} * 30 \mathrm{~m}$ resolution for the six LST images by using the Geostatistical toolset in ArcGIS 10.5. Then, LST pixels with $270 \mathrm{~m}$ interval were extracted and converted to points by systematic sampling to get independent LST observations, which were then overlaid to LCZs maps.

Overall differences of mean LST of each LCZ among all the 17 LCZs were explored by one-way analysis of variance (ANOVA). After we were confirmed the overall statistically significant differences for LCZs in terms of their LST, we further identified the specific LCZs which differed with others regarding their LST character with Tukey HSD test for the three metropolitans.

To further make comparison of the SUHI intensity by incorporating LCZs map, "Distribution Index" (DI) method were adopted to explore the relative contribution of individual LCZs to the entire SUHI phenomenon of the metropolitans (Peng, Xie et al. 2016). We particularly focused on "high" LST pixels as a direct indicator of the SUHI phenomena. To quantify "high" LST level, the original LSTs were normalized and categorized by four levels from "cool" to "hot" with Jenks natural breaks classification scheme (Weng, Liu et al. 2008).

$$
D I_{L C Z_{i}}=\frac{S H i g h_{L C Z_{i}} / s_{L C Z_{i}}}{S H i g h / S}
$$

where $i$ means the individual $\mathrm{LCZ}$, ranging from 1 to $\mathrm{F}$. "SHigh ${ }_{L C Z_{i}} / S_{L C Z_{i}}$ " refers to the proportion of the area with high LST $\left(\operatorname{SHigh}_{L C Z_{i}}\right)$ in the area of a LCZ. "SHigh/S" refers to the proportion of the area with high LST in the entire metropolitan area $(S)$. A DI value equals 1 means an average contribution to the overall hot environment of SUHI phenomenon. Therefore, for the LCZ 1 to $\mathrm{LCZ} \mathrm{G,} D I_{L C Z_{i}}$ higher than 1 means this $\mathrm{LCZ}_{\mathrm{i}}$ has a heating effect on the SUHI, while DILCZi lower than 1 means the $\mathrm{LCZ}_{\mathrm{i}}$ has a cooling effect on the SUHI of the metropolitan area. 


\section{RESULTS AND DISCUSSION}

\subsection{LCZs Mapping Result}

Overall, the LCZs distributions shows spatial dependency character for the entire metropolitan, with LCZ 1-10 "built-up cover" types generally surrounded by LCZs A-G "natural cover" types (Figure 2). The LCZs mapping results were overlaid with the high resolution historical Google Earth imagery to evaluate our mapping accuracy. Most of our LCZs were matched correspondingly with the illustrations in Google Earth.

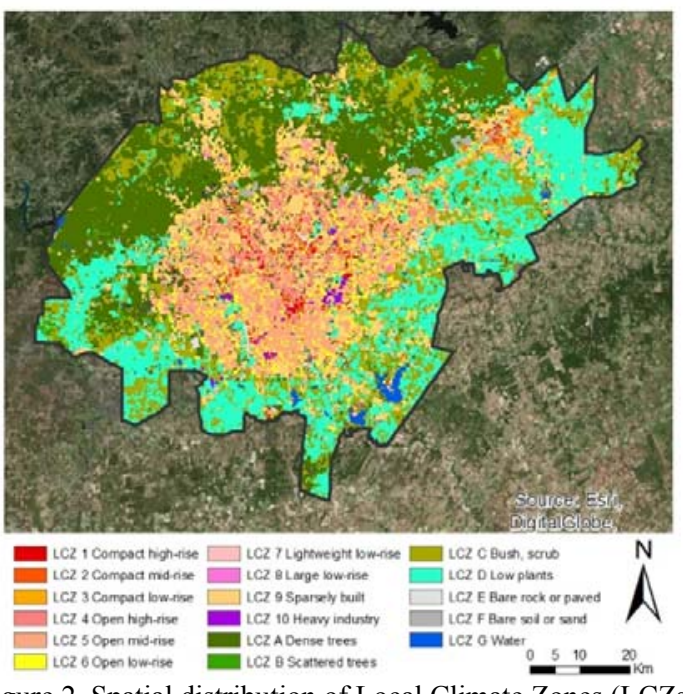

Figure 2. Spatial distribution of Local Climate Zones (LCZs) for San Antonio, Texas. (Note: the labels on the map is the location of the illustrated sites in the detailed examination at Google Earth)

The LCZs 1-10 are compactly distributed in the central urbanized area. The high buildings in San Antonio are loosely distributed, leading to a larger proportion of LCZ 5 Open mid-rise intersect with LCZ 6 Open low-rise. As the oldest city with landmark events and a slower pace of economic development, San Antonio-New Braunfels metropolitan has maintained this diversely distributed urban form. However, there is limited area regarding the LCZ 3 Compact low-rise and LCZ 4 Open highrise; thus we dropped these two types LCZs in the subsequent analysis.

The sounding rural areas show a large percentage of LCZ A and LCZ B, besides of LCZ D. LCZ A Dense trees is the typical LCZ at eastern part, while the LCZ B Scattered trees is concentrated at southern part and LCZ D Low plants is concentrated at the western part. There is a clear contrast of the northern and southern part, dominated by LCZ A Dense trees and LCZ D Low plants, respectively. This spatial distribution is accordance with the underlying land cover showed by background high resolution imagery.

The integration of Lidar data helped to incorporate detailed urban and vegetation morphology information for LCZs mapping at the scope of the metropolitan. This is in contrast to the results provided by direct object-based image analysis or supervised pixel-based classification techniques. So far, there has only been one study using Lidar data for LCZs mapping, and it was conducted within a small portion of suburban Sydney, Australia, owing mainly to the time and expense limitations of data acquisition (Koc, Osmond et al. 2017). With the popularity and free availability of Lidar datasets and updated NLCD in the U.S., our study provides evidence that the automated GIS-based LCZs mapping using Lidar-derived products can be replicable to other cities in the U.S. by overcoming the data insufficiency issue regarding the 3D urban morphological information.

\subsection{Linking LCZs with LST}

On July 22, 2015, there is an obvious SUHI phenomenon of San Antonio (Figure 3). High surface temperature is highly associated with both downtown area and isolated urbanized areas, while low surface temperature occurred at the northern San Antonio, where the forestry area prevailed. The coolest LST was correspondent with the water body coverage (e.g., Lake Travis in Austin and Calaveras Lake in San Antonio). The spatial distributions of LCZs and LST indicated that the LCZs and LST can be connected to further investigate the SUHI.

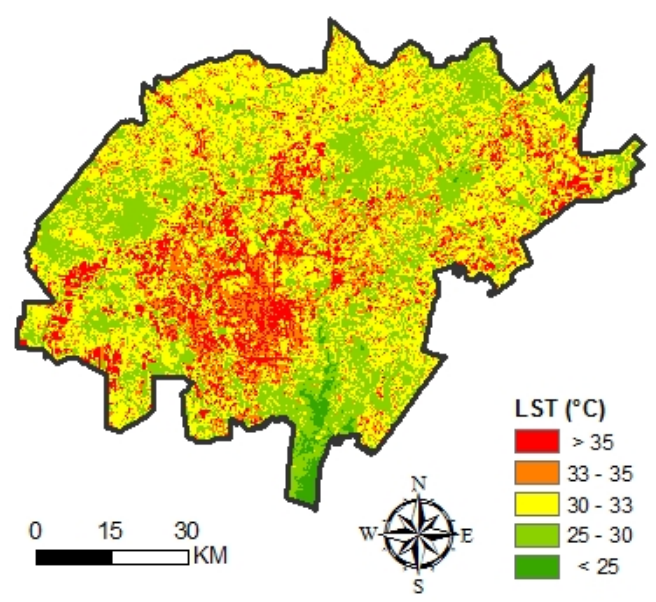

Figure 3. Spatial distribution of land surface temperature (LST) in the San Antonio metropolitan on July 22, 2015

The statistical summary indicated considerable differences among LCZs in terms of the average LST (Figure 4). LSTs at LCZs 1-10 "built-up cover" types were generally higher than that of LCZs A-G "natural" cover types at July 20, 2015 for entire metropolitan. Regarding the LST variation among LCZs with contrasting urban morphology, LCZs Compact (e.g., LCZ 1 and LCZ 2) showed the highest temperature than other LCZs types. LCZ 4 Open high-rise, LCZ 5 Open mid-rise, and LCZ 6 Open low-rise also indicates relatively warmer surface temperature. On the other hand, the LCZs high-rise generally exhibits higher LSTs than LCZs mid-rise or low-rise types (e.g., LCZ 1 vs LCZ 2; LCZ 4 and 5 vs LCZ 6). LCZ 9 Sparsely built has the lowest temperature due to the vegetation cooling effect. Compared to other LCZs "built-up cover" types, LCZ 10 Heavy industry, demonstrated higher LST variation (long boxes in Figure 4). Compared to the above distinguishable LCZs, LCZ 10 Sparsely built, demonstrated higher LST variation, which can be explained by the fact that LCZ 10 was also "sparsely" distributed and contiguous with other LCZ types throughout the study areas (Figure 2). 


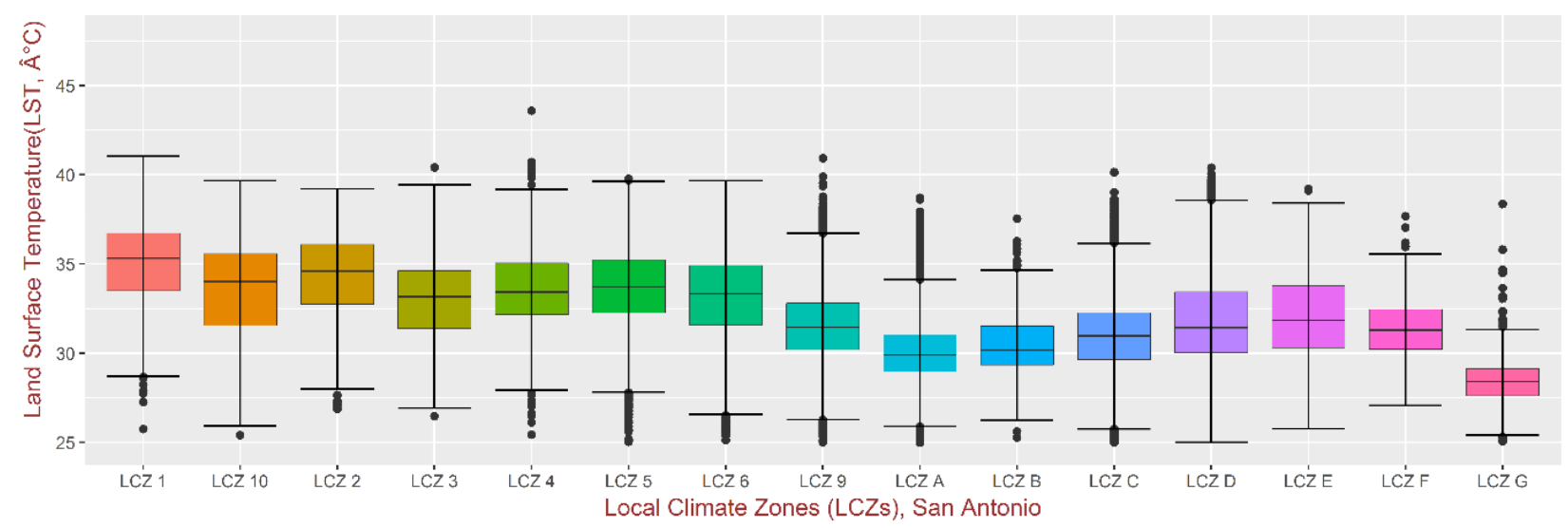

Figure 4. Box-plots summary of LST values for individual LCZs for entire metropolitan at July 20, 2015. (Note 1. References for LCZs: LCZ 1 Compact high-rise; LCZ 2 Compact mid-rise; LCZ 5 Open mid-rise; LCZ 6 Open low-rise; LCZ 7 Lightweight lowrise; LCZ 8 Large low-rise; LCZ 9 Sparsely built; LCZ 10 Heavy industry; LCZ A Dense trees; LCZ B Scattered trees; LCZ C Bush, scrub; LCZ D Low plants; LCZ E Bare rock or paved; LCZ F Bare soil or sand; LCZ G Water. Note 2. The line within each box represents the median of LST values at the corresponding LCZ, and the bottom of the box indicates the first quartile of LST values, and the top indicates the third quartile of LST values)

LST values were also examined regarding the distribution density for each LCZs to check the normalization to support the assumption of the subsequent ANOVA analysis. Most of the LST distribution follows the normalized distribution except LCZ G Water. Along with the higher variation and more outliers showed by box-plots, significant departures from the mean LST were also demonstrated for the LCZ G Water.

Apparently, owing to the highest heat capacity of water compared to other surface property, LCZ G Water had the lowest average LST among all LCZ classes with values lower than $40{ }^{\circ} \mathrm{C}$ for all six LST images, except for that at August 31, 2013, for Austin. Nevertheless, different water bodies were also delineated into LCZ G, and some water body does not have enough volume to cool down the surface temperature at around 5:00 PM of a day. Meanwhile, some types of water body (e.g., creeks, rivers, etc.) are more vulnerable to the climate and environment and changeable throughout the time compared to other land surface properties, and some area may not belong to LCZ G Water at the LST acquisition time, considering our LCZs is built by data collected during 2007-2013. The outliers and LST variation within LCZ G Water were also explained by Geletič, Lehnert et al. (2016).

The results of the one-way ANOVA F-test demonstrated that the differences among different LCZs are different in terms of the surface temperature $(\mathrm{p}<0.001)$ (Table 3$)$. In addition, the Tukey Honestly Significant Difference (HSD) test was presented in the Figure 5.

\begin{tabular}{|c|c|c|c|c|}
\hline DF & SSM & SSR & F & P \\
\hline 16 & 1258407 & 1446511 & 5743 & $<2 \mathrm{e}-16^{* * *}$ \\
\hline
\end{tabular}

Table 3. The summary of ANOVA for testing the difference of local climatic zones (LCZs) in terms of the land surface temperature (LST). DF: Degrees of Freedom; SSM: Sum of Squares of Model; SSR: Sum of Squares of Residuals

Most of the pairs of LCZs show significant differences in average LSTs with high significant level. It indicates that our LCZs mapping can help to identify homogenous zones in terms of its surface temperature, and these zones are different with each other. Here, the number noted at diagonal is the counts of empty spaces for the corresponding LCZs. For the 13 pairs of LCZs, LCZ 1 Compact high-rise, LCZ 10 Heavy industry, LCZ G Water were all distinguished very well regarding their surface temperature. There are only four LCZs which cannot be distinguished with another two LCZs, including LCZ 5 Open mid-rise, LCZ B Scattered trees, LCZ E Bare rock or paved, and LCZ F Bare soil or sand.

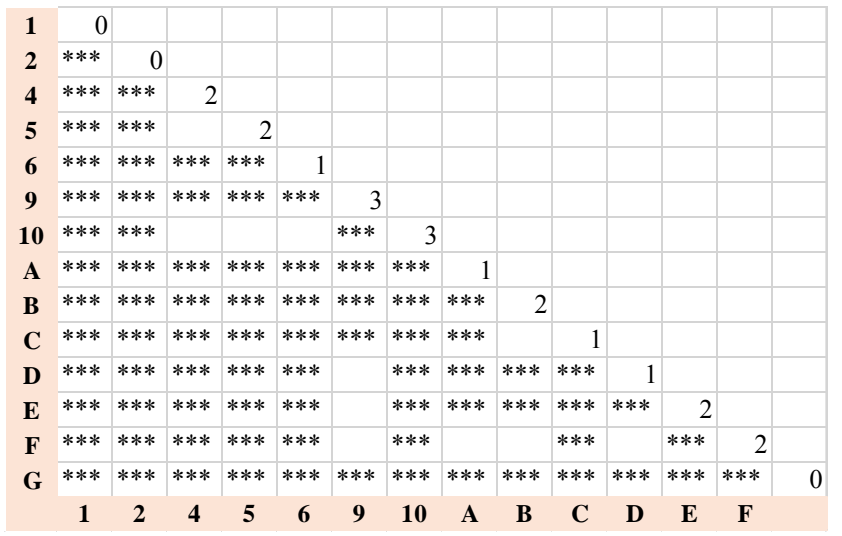

Figure 5. Tukey Honestly Significant Difference (HSD) test result for LCZs in terms of the surface temperature differences. (Note: Please refer to the name of LCZs from Figure 4. '***': significance at 0.001 level for that pair of LCZs; '*':

significance at 0.05 level for that pair of LCZs; Empty space: no significant difference of the corresponding LCZs pairs. The number noted at diagonal is the counts of empty spaces for the corresponding LCZs)

We adopted DI value related to "high" LST pixels to compare the SUHI intensity at July 20, 2015, for different LCZs within the metropolitan (Figure 6). DI value further proved and manifested the heterogeneity of the contributions to the thermal environment by different LCZs. In terms of the effect of individual LCZ for the overall SUHI high temperature effect, LCZ G water had DI values near 0 , meaning that there is almost "low" LST pixels in the normalized LST map at July 20, 2015. Hence, LCZ G played the most significant role in mitigating the SUHI effect. Besides, 
other LCZ "natural cover" types had lower DI value than 1. In contrast, LCZs 1-10 "built-up cover" types all had DI values higher than 1 at July 20, 2015, except for LCZ 9 Sparsely built. With different level of cooling effect or detrimental impact, the DI value results show that the LCZs mapping contributes to SUHI investigation.

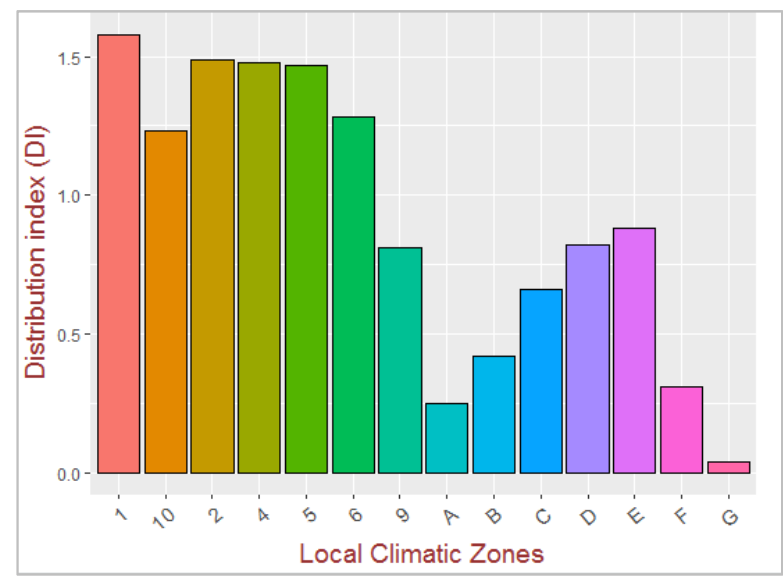

Figure 6. Distribution index (DI) of high temperature centres for LCZs in the metropolitan at July 20, 2015 (Note: Please refer to the name of LCZs from Figure 4)

However, further investigation of the SUHI phenomenon at night time still needed, and to further investigate the overall relationship of building morphology and LST, more information regarding the locations, size, materials, and functions of the buildings are still needed. In addition, the LCZs compact exhibits higher LSTs than LCZs open types, which can also be explained by the shading effect.

\section{CONCLUSIONS}

Our study showed the advantage of LCZs mapping on understanding SUHI, which looks into the temperature differentiation among LCZ classes rather than among the traditional "urban" and "rural" classes. The linkage of LCZs and LST proved that the LCZs mapping can be used to compare and investigate the SUHI. Most of the pairs of LCZs show significant differences in average LSTs with high significant level. The intra-urban temperature comparison among different urban classes contributes to investigate the influence of heterogeneous urban morphology on local climate formation.

As a standard method to support AUHI and SUHI investigation, these high-quality LCZs maps gives a better understanding of the urban thermal environment, which can further benefit spatially specific AUHI and SUHI migration strategies. Moreover, they can further be incorporated into climatic models to understand the UHI dynamics and formulation with detailed underlying surface information. It can also facilitate comparative analysis of SUHI studies for different areas.

\section{REFERENCES}

Bremer, T. S., 2004. Blessed with tourists: The borderlands of religion and tourism in San Antonio, Univ of North Carolina Press.
Cai, M., Ren, C., Xu, Y., Lau, K.K.L. and Wang, R., 2017. Investigating the relationship between local climate zone and land surface temperature using an improved WUDAPT methodology - A case study of Yangtze River Delta, China. Urban Climate. https://doi.org/10.1016/j.uclim.2017.05.010

Geletič, J. and Lehnert, M., 2016. GIS-based delineation of local climate zones: The case of medium-sized Central European cities. Moravian Geographical Reports, 24(3), pp. 2-12, https://doi.org/10.1515/mgr-2016-0012

Geletič, J., M. Lehnert and Dobrovolný, P., 2016. Land Surface Temperature Differences within Local Climate Zones, Based on Two Central European Cities. Remote Sensing, 8(10), p 788. https://doi.org/10.3390/rs8100788

Howard, L., 1818. The Climate of London: deduced from Meteorological observations, made at different places in the neighbourhood of the metropolis (1). W. Phillips, sold also by J. and A. Arch.

Hu, L. and Brunsell, N.A., 2015. A new perspective to assess the urban heat island through remotely sensed atmospheric profiles. Remote Sensing of Environment, 158, pp.393-406.

Koc, C.B., Osmond, P., Peters, A. and Irger, M., 2017, March. Mapping Local Climate Zones for urban morphology classification based on airborne remote sensing data. In Urban Remote Sensing Event (JURSE), 2017 Joint (pp. 1-4). IEEE.

Kotharkar, R. and Bagade, A., 2017. Local Climate Zone classification for Indian cities: A case study of Nagpur. Urban Climate. https://doi.org/10.1016/j.uclim.2017.03.003

Mirzaei, P.A., 2015. Recent challenges in modeling of urban heat island. Sustainable Cities and Society, 19, pp.200-206.

Nichol, J.E., 1996. High-resolution surface temperature patterns related to urban morphology in a tropical city: A satellite-based study. Journal of Applied Meteorology, 35(1), pp.135-146.

Nunez, M. and Oke, T.R., 1977. The energy balance of an urban canyon. Journal of Applied Meteorology, 16(1), pp.11-19.

Oke, T.R., 1976. The distinction between canopy and boundarylayer urban heat islands. Atmosphere, 14(4), pp.268-277.

Peng, J., Xie, P., Liu, Y. and Ma, J., 2016. Urban thermal environment dynamics and associated landscape pattern factors: A case study in the Beijing metropolitan region. Remote sensing of environment, 173, pp.145-155.

Shen, H., Huang, L., Zhang, L., Wu, P. and Zeng, C., 2016. Longterm and fine-scale satellite monitoring of the urban heat island effect by the fusion of multi-temporal and multi-sensor remote sensed data: A 26-year case study of the city of Wuhan in China. Remote Sensing of Environment, 172, pp.109-125.

Sobrino, J.A., Jiménez-Muñoz, J.C. and Paolini, L., 2004. Land surface temperature retrieval from LANDSAT TM 5. Remote Sensing of environment, 90(4), pp.434-440. 
Stewart, I.D., Oke, T.R. and Krayenhoff, E.S., 2014. Evaluation of the 'local climate zone'scheme using temperature observations and model simulations. International Journal of Climatology, 34(4), pp.1062-1080.

Stewart, I.D. and Oke, T.R., 2012. Local climate zones for urban temperature studies. Bulletin of the American Meteorological Society, 93(12), pp.1879-1900.

Unger, J., Lelovics, E. and Gál, T., 2014. Local Climate Zone mapping using GIS methods in Szeged. Hungarian Geographical Bulletin, 63(1), pp.29-41.

Weng, Q., Liu, H., Liang, B. and Lu, D., 2008. The spatial variations of urban land surface temperatures: pertinent factors, zoning effect, and seasonal variability. IEEE Journal of Selected
Topics in Applied Earth Observations and Remote Sensing, 1(2), pp.154-166.

Xie, H., Guan, H. and Ytuarte, S., 2005, October. Heat island of San Antonio, Texas detected by MODIS/Aqua temperature product. In Proceedings of the 20th Biennial Workshop on Aerial Photography, Videography, High Resolution Digital Imagery for Resource Assessment. Weslaco, TX.

Zheng, Y., Ren, C., Xu, Y., Wang, R., Ho, J., Lau, K. and Ng, E., 2017. GIS-based mapping of Local Climate Zone in the highdensity city of Hong Kong. Urban Climate. https://doi.org/10.1016/j.uclim.2017.05.008

\section{APPENDIX}

\begin{tabular}{|c|c|c|c|c|}
\hline Project Name & $\begin{array}{l}\text { Point } \\
\text { Space } \\
(\mathrm{cm}) \\
\end{array}$ & $\begin{array}{l}\text { Horizontal/Vertical } \\
\text { Accuracy } \\
(\mathrm{cm}, \mathrm{MSE})\end{array}$ & $\begin{array}{l}\text { Horizontal/ } \\
\text { Vertical Datum }\end{array}$ & Units \\
\hline FEMA 2011 Comal, Guadalupe & 100 & $\begin{array}{l}60 / \\
12.5\end{array}$ & $\begin{array}{l}\text { NAD83, NSRS2007/NAVD88, } \\
\text { Geoid09 }\end{array}$ & Meters \\
\hline StratMap 2010 Bexar & 50 & $\begin{array}{l}100 / \\
19\end{array}$ & NAD83/NAVD88, GEOID 09 & Meters \\
\hline $\begin{array}{l}\text { CAPCOG } 2007 \text { Caldwell, Travis, } \\
\text { Williamson }\end{array}$ & 140 & $\begin{array}{l}100 / \\
18.5\end{array}$ & $\begin{array}{l}\text { NAD83/ } \\
\text { NAVD88 }\end{array}$ & Feet \\
\hline $\begin{array}{l}\text { CAPCOG } 2008 \text { Bastrop, Fayette, } \\
\text { Hays }\end{array}$ & 140 & $\begin{array}{l}100 / \\
18.5-37\end{array}$ & $\begin{array}{l}\text { NAD83/ } \\
\text { NAVD88 }\end{array}$ & Feet \\
\hline
\end{tabular}

Table A1. Metadata of Lidar projects for the study area 